\title{
Design \& Fabrication of Sterling Engine with Solar Concentrator for Power Generation
}

\author{
Dr. A.H. Ingle ${ }^{1}$, Rimanshu Fating ${ }^{2}$, Abhijit Chatur ${ }^{3}$, Hasin Bagde ${ }^{4}$, Devendra Rahangdale ${ }^{5}$ \\ ${ }^{1}$ Associate Professor, ${ }^{2,3,4,5}$ Students \\ Department of Mechanical Engineering, Smt. Radhikatai Pandav College of Engineering, Nagpur, Maharashtra, India.
}

Received on: 30 May, 2021

Revised on: 01 July, 2021

Published on: 03 July, 2021

\begin{abstract}
The article focuses on performance of Stirling system. The performance depends on the capacity. The article focuses on the performance of the Stirling system. The performance depends on the capacity of the sterling engine and also on the location where the system is being used.The model is used to determine the power consumption and to forecast the net power that will be produced. Basically, a sterling engine is an engine that works on the heat that is being taken from the sun or other heat radiating mediums. The heat energy is converted to mechanical work. a generator is also coupled with a rotating flywheel which also rotates the generator to produce power.
\end{abstract}

Keywords: Stirling, Solar Thermal Power, Performance, Energy Conversion Efficiency.

\section{I- INTRODUCTION}

$\mathbf{I}_{\mathrm{n}}$ nterest in renewable energy is growing at a rapid pace as people are getting aware of the harmful effects of conventional power sources on the environment and also on their lives as more and more pollution is being spread in the air that everyone breathes. Solar energy is one of the most attractive renewable energy sources as it is available in the market for a long time and also a lot of development is being done from time to time to improve its efficiency in producing energy from sunlight. Solarpowered Stirling engine systems are still considered the most effective systems in converting solar energy when compared to other available systems. The conversion efficiency of the Stirling dish system is $29.4 \%$ (net solar to electric energy).it is worth noting that efficiency is defined as net electric power delivered subtracting the electric power needed by parasitic dividing it by DNI(Direct Power Irradiance) incident on the area of mirrors. Riyadh in Saudi Arabia has already installed two $17 \mathrm{~m}$ dia. Stirling dish systems each having a capacity of 50KWe.The net electrical output of 53KW and net conversion efficiency of $23 \%$ are being successfully achieved by the system at the isolation of $1000 \mathrm{~W} / \mathrm{m} 2$.Recently a large dish . Stirling plant was constructed in Arizona united states the total dish installed at that time was 60 in no with a capacity of $25 \mathrm{KWe}$ (per dish) and a total capacity of $1.5 \mathrm{MWe}$.

Solar Dish Stirling engine generally has a great potential of producing a large amount of energy in areas that receives huge solar radiation throughout the year. Parabolic trough when compared with Stirling dish system are less efficient and are less economical and has lower efficiency so using Stirling dish system is a good choice by far. Till this time we have concentrated more on other solar technologies but failed to look in the direction of Stirling dish systems which could have been 


\section{International Journal of Innovations in Engineering and Science, www.ijies.net}

proven effective in providing energy and also a clean future. Different heat sources can be combined with them in one application so this makes them very useful for hybrid operations. The parabolic dish used in the system can concentrate only in one direction so a twoaxis tracking system would be required to keep the track of the sun's radiation continuously. A highly Efficient solar to electric system conversion system can be achieved only when high temperatures are obtained from high concentration ratios. In a practical system, the range of solar to electric efficiency is between $16 \%$ to $30 \%$. For electric generation, a stand-alone dish Stirling engine system can also be used. Research is focused on showing that the Stirling engine is capable of generating energy just like solar panels and can be used just like any other renewable energy device which would be used to power various appliances in our homes. The hightemperature differential dish could reach up to $34 \%$ efficiency. HIgh-temperature Stirling engines are pricy as they require expensive materials and careful selection and also the high-cost solar collector is required for a high concentration ratio

\section{II- SYSTEM DESCRIPTION}

The Stirling dish system uses concentrated solar thermal energy to produce electricity to drive the Stirling engine. The system is composed of components like a) Fresnel lens, b) Stirling engine, c) generator. The system utilizes a Fresnel lens to concentrate solar radiation onto a heating cylinder integrated into the Stirling engine. The absorbed solar energy to the working fluid in the Stirling engine is done with the help of the receiver. Absorbed thermal energy is converted into mechanical power by compressing the working fluid when cool expanding when hot. The linear motion is converted to a rotary motion by driving mechanisms to run a generator to produce electricity. The key to conversion efficiency is solar radiation concentration if it lowers would affect the efficiency and rate of production.

\section{III - METHODOLOGY}

\section{III.1:- Stirling Engine}

Stirling engine consists of a fixed mass of gas called working fluid the engine is a closed cycle. helium hydrogen is commonly used. The power stroke is produced whenever the gas gets heated the heat rises and also the pressure rises.

\section{III.2. Flywheel}

The main function of the flywheel is to store energy generated by the power stroke of the cycle and returns it to the crankshaft when the pistons reach their full length. This makes the piston move continuously without locking inside the engine.

\section{III.3. Generator}

To convert mechanical to electricity we need a device called a generator. The generator comes in all categories (high to low voltage output) from alternating current to direct current. Conversion of energy in generator happens with the help of center rotor that is surrounded by stator magnets, stator magnet generates a magnetic field. Rotor interacts with an electromagnet or a permanent magnet to generate electric current. The current that is produced is either direct current (DC) or alternating current (AC). Switch that enables the flow of current to reverse itself when the electrical cycle is completed, which then it produces the direct current flow..

\section{III.4.Piston}

The displacer is a special-purpose piston, used in Beta and Gamma type Stirling engines, to move the working gas back and forth between the hot and cold heat exchangers.

\section{III.5 Drive Wheel}

The drive wheel is attached to the generator with the drive tape which transfers circular motion to the generator to rotate the in build motor to rotate and generate power.

\section{III.6 Alcohol Lamp}

Alcohol lamp is used to provide heat in case if direct sunlight is not available or absent due to weather. Lamp provides direct heat which heats the tube which in turn heats the inner air inside the tube.

\section{III.7 Fresnel Lens}

Several renewable energy sources were searched by us. Our preliminary list included 13 possible heat sources we would potentially tap into. After weighing the pros and cons of each, we considered Fresnel lens as our choice. In 1748, Georges-Louis Leclerc de Buffon came up with the idea to create a lens composed of several concentric circles. Sometime later in 1821, this idea was improved upon by Augustin - Jean Fresnel as a way to create lighthouse lenses. This was a highly effective 


\section{International Journal of Innovations in Engineering and Science, www.ijies.net}

technique and has remained relatively unchanged. Fresnel lens is arranged in concentric rings arranged on a flat surface to provide a short focal length. they are mainly used in lighthouses and searchlights.

\section{IV -STRILING CYCLE ANALYSIS}

IV.1. Ideal Cycle

\begin{tabular}{|l|l|l|l|}
\hline P 1 & $97 \mathrm{kPa}$ & V 1 & $299.77 \mathrm{cc}$ \\
\hline P 2 & $111.84 \mathrm{kPa}$ & V 2 & $260 \mathrm{cc}$ \\
\hline P 3 & $166.44 \mathrm{kPa}$ & V 3 & $260 \mathrm{cc}$ \\
\hline P 4 & $143.49 \mathrm{kPa}$ & V 4 & $299.77 \mathrm{cc}$ \\
\hline
\end{tabular}

$$
\begin{aligned}
\text { Wnet }= & \mathrm{mR}(\mathrm{T} \mathrm{h}-\mathrm{Tc}) \\
& \ln (\mathrm{Vmax} / \mathrm{Vmin}) \\
= & 2.212 \mathrm{~J} \\
\text { Pnet }= & \text { Wnet } * \text { Speed } \\
= & 5.74 \text { Watts } \\
\text { Pnet }= & \text { Wnet } * \text { Speed } \\
= & 5.74 \text { Watts }
\end{aligned}
$$

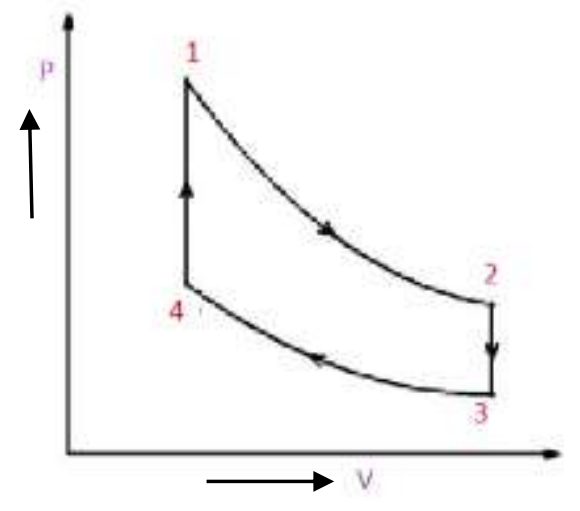

\section{IV.2. Stirling Cycle Is Comprised Of Four Stages}

\section{Process 1-2}

It is isothermal heat addition process. Volume of the system increases due to isothermal heat addition. A little drop in pressure also happens in this process.

\section{Process 2-3}

It is isochoric heat removal process. Both temperature and pressure of the system decreases due to isochoric heat removal.

\section{Process 3-4}

It is isothermal heat removal process. It is a compression process hence pressure of the system increases and volume decreases.

\section{Process 4-1}

It is isochoric heat addition process. Both temperature and pressure of the system increases due to isochoric heat addition.

\author{
IV.3. Stirling Cycle Analysis \\ Real Cycle (Schmidt Analysis) \\ Schmidt Factor: \\ Fs $=0.74-0.68 \delta=0.559$ \\ $\delta=\mathrm{VD} / \mathrm{VSW}=0.266$ \\ Actual Power $=$ FS $*$ Ideal Power $=0.559 * 5.74$ \\ $=3.2$ Watts
}

\section{V- DESIGN CALCULATION:}

\section{V.1. Volume Calculation}

Clearance volume $=$ volume of cylinder - volume of displacer

$$
\begin{aligned}
& =(\pi / 4) \mathrm{D} 2 \mathrm{~L}-(\pi / 4) \mathrm{d} 2 \mathrm{l} \\
= & (\pi / 4) * 4.82 * 25-(\pi / 4) * 4.52 * 12.4 \\
= & 255.176 \mathrm{cc}
\end{aligned}
$$

V.2. Kolin's Rule of thumb, Volume Ratio, VR $=(1+\mathrm{dT} / 1100)$

$\mathrm{dT}=150$ degree centigrade

$\mathrm{VR}=(1+150 / 1100)$

$$
=1.13636
$$

Volume Ratio: $\quad \mathrm{Vc}+\mathrm{Ve} / \mathrm{Vc}$

Expansion volume: $\mathrm{Ve}=\mathrm{Vc}(\mathrm{VR}-1)$

$$
\begin{aligned}
& =255.176(1.13636-1) \\
& =34.8 \mathrm{cc}
\end{aligned}
$$

\section{Stroke Length}

Cross-sectional area of the power piston $=(\pi / 4) * 2.92=$ $6.6 \mathrm{~cm} 2$

$\mathrm{Ve}=\mathrm{c} / \mathrm{s}$ area of power piston $*$ Stroke length of power piston Therefore, $\Upsilon$

Stroke length $=34.8 / 6.6=5.27 \mathrm{~cm}(6 \mathrm{~cm})$

\section{VI- RESULTS}

Max electrical Efficiency $=24 \%$

Average Thermal Efficiency $=58 \%$

Max efficiency of sterling engine $=73 \%$

Average temperature of combustion chamber $=100 \mathrm{c}$

Pressure inside cylinder $=80 \mathrm{bar}$

Rotational speed rpm=1600rpm 
Vol. 6, No. 8, 2021, PP. 04 - 07

International Journal of Innovations in Engineering and Science, www.ijies.net

\section{VII- CONCLUSION}

Finally we have Sterling engine with Solar Concentrator that can generate electrical energy with $17 \%$ efficiency. There is a possibility to use a sterling engine as we are using solar panels to power our homes and their appliances with the use of a sterling engine. The sterling engine can also be used in combination with solar panels to lower the dependency on the utility grid.

\section{REFERENCE}

[1] Kolin, Ivo."'Stirling Motor - History, Theory, Practice". Dubrovnik : Zagreb University Publications, Ltd., 1991.

[2] Khurmi, Gupta, "A Textbook of Machine Design”, 2005 edition

[3] Shigley, Mischke, "Mechanical Engineering Design", Sixth Edition.

[4] William R. Martini,"STIRLING ENGINE DESIGN MANUAL", University of Washington-April, 1978.

[5] Koichi HIRATA, "Development of a Small $50 \mathrm{~W}$ Class Stirling Engine”. 